\title{
Social Interaction Deficits Caused by Chronic Phencyclidine Administration are Reversed by Oxytocin
}

\author{
Paul R Lee', Dana L Brady², Robert A Shapiro ${ }^{3}$, Daniel M Dorsa ${ }^{3}$ and James I Koenig*, I,2 \\ 'Program in Neuroscience, Maryland Psychiatric Research Center, University of Maryland Medical School, Baltimore, MD, USA; ' ${ }^{2}$ Department of \\ Psychiatry, Maryland Psychiatric Research Center, University of Maryland Medical School, Baltimore, MD, USA; ${ }^{3}$ Department of Physiology and \\ Pharmacology, Oregon Health and Science University, Portland, OR, USA
}

\begin{abstract}
Chronic administration of phencyclidine (PCP) has been advanced as a valid animal model of the social deficit symptoms of schizophrenia. In these studies, the cumulative time that male rats treated once a day for 14 days with PCP actively engaged in social behavior was decreased approximately $75 \%$ relative to saline-treated control animals. In addition, these socially impaired rats had an increase in the relative amount of noncontact interactions compared with saline-injected peers. Social behaviors were preferentially affected by PCP treatment because in two anxiety-related behavioral assays, the open field and light/dark emergence tests, there was a failure to differentiate between the PCP-treated rats and saline-injected control rats. Considering the general importance of the neuropeptides oxytocin and vasopressin in male social behaviors, studies of molecular markers related to these neuropeptides were performed. Hypothalamic oxytocin mRNA expression was significantly decreased while oxytocin receptor binding was increased in the central nucleus of the amygdala following chronic PCP treatment. Given the significance of central nucleus of the amygdala in social behavior, oxytocin was infused into the central nucleus of experimental and control male rats, and their postinfusion social interaction and open field behaviors were analyzed. A bilateral infusion of I $\mu \mathrm{g}$ of oxytocin into the central amygdala selectively restored the normal quantity and quality of social behavior in chronic PCP-treated male rats without altering open field behaviors. These findings suggest that deficits in the central oxytocinergic system may underlie the social impairment exhibited in this animal model of schizophrenia. Neuropsychopharmacology (2005) 30, I 883- 1894. doi: I 0. I 038/s..npp. I 300722; published online 30 March 2005
\end{abstract}

Keywords: oxytocin; amygdala; rats; hypothalamus; social interaction; schizophrenia; NMDA receptor

\section{INTRODUCTION}

Schizophrenia is a complex neuropsychiatric disease in which both genetics and the environment have significant roles in the etiopathophysiology of the illness. Current investigations are taking advantage of recent knowledge about the etiology of schizophrenia to advance the development of animal models for this perplexing disease. These models attempt to emulate aspects of schizophrenia through imitation of symptoms (so-called 'face validity'), through examination of the outcomes associated with a putative risk factor ('construct validity'), through predictions of treatment responsiveness ('predictive validity'), or some combination of these possibilities (Lipska and Weinberger, 2000). To date, however, few animal models

\footnotetext{
*Correspondence: Dr JI Koenig, Department of Psychiatry, Maryland Psychiatric Research Center, University of Maryland Medical School, PO Box 21247, Baltimore, MD 21228, USA, Tel: + I 4104027319 , Fax + I 4I0 402 6066, E-mail: jkoenig@mprc.umaryland.edu Received 27 August 2004; revised 3 February 2005; accepted 4 February 2005

Online publication: 16 February 2005 at http://www.acnp.org/citations/ NPP02 I 60504039|/default.pdf
}

have been described with face validity for schizophrenia's social withdrawal. Of the attempts to model the social incompetence of schizophrenia, three models exploit genetic changes putatively associated with schizophrenia and involve manipulation of the calcineurin A, Dishevelled1, and NMDA receptor NR1subunit genes in mice (Miyakawa et al, 2003; Lijam et al, 1997; Long et al, 2004; Mohn et al, 1999).

Nongenetic models employ a more traditional pharmacological strategy based on the growing body of evidence postulating that diminished glutamate neurotransmission at $N$-methyl-D-aspartate (NMDA) receptors is a pathological component of schizophrenia (Malhotra et al, 1997). Reducing NMDA receptor-mediated neurotransmission in the human brain causes severe behavioral disturbances resembling schizophrenia. For example, ketamine, a NMDA receptor antagonist similar to phencyclidine (PCP), creates a dissociative psychosis in normal volunteers (Krystal et al, 1994; Newcomer et al, 1999); ketamine also alters regional cerebral blood flow in a manner similar to that which is detected during an acute episode of schizophrenia (Lahti et al, 1995). NMDA antagonism can worsen positive and negative symptoms in patients diagnosed with schizophrenia (Javitt and Zukin, 1991). Finally, agonists at the glycine 
site of the NMDA receptor (ie glycine, D-cycloserine, and serine) have been shown to be effective adjunctive treatments in schizophrenia; they have particular efficacy in improving ratings of negative symptoms (Evins et al, 2002; Heresco-Levy et al, 2004; Tsai et al, 1998). Pharmacological blockade of NMDA receptors in animals using selective noncompetitive NMDA antagonists such as MK801 or PCP has yielded compelling neurochemical findings that are consistent with pathological findings in schizophrenic post-mortem investigations and suggest that repeated PCP treatment induces neuroplastic changes in several brain regions. Jentsch et al $(1997,1999)$ have noted in rats and apes that chronic PCP treatment activates the mesolimbic dopamine pathway and produces lasting deficits in prefrontal cortical function. These findings are consistent with data from schizophrenic patients (for a review, Finlay, 2001). PCP-related changes are certainly not limited to the dopaminergic system. Following chronic PCP treatment, there are signs of a compensatory attempt to overcome the reduction in glutamate neurotransmission. NR1 mRNA expression is greatly increased in the prefrontal cortex, nucleus accumbens, and anterior striatum of the rat $72 \mathrm{~h}$ after chronic administration of PCP has ceased (Wang et al, 1999); the number of NR1-immunoreactive cells is increased in the anterior striatum and prefrontal cortex (Hanania et al, 1999). The expression of NMDA receptor subunit mRNA, including NR1 mRNA, have been found to be reduced in post-mortem schizophrenic cortex (Akbarian et al, 1996), which correlate with diminished cognitive function (Humphries et al, 1996). However, others have reported increased expression of NR1 mRNA in other human brain samples (Gao et al, 2000). The fact that chronic PCP administration alters NMDA receptor expression and induces lower glutamatergic neuronal function is a possible pathological component of schizophrenia and an important validation of this model's appropriateness and utility.

Behaviorally, chronic PCP administration to male rats reduces the time animals spend in social interaction (SamsDodd, 1995, 1997; Qiao et al, 2001); the mechanism involved in this behavioral change has not been explored. Interestingly, the NR1 knockdown mice also have significant social abnormalities. These mice maintain large distances from wild-type littermates and actively avoid social investigation when used as the residents in a resident-intruder paradigm (Mohn et al, 1999). In both chronic PCP treated animals and the NR1 knockdown mice, the atypical antipsychotic drug, clozapine, which appears to treat negative symptoms and social deficit symptoms better than other treatments (Azorin et al, 2001; Buchanan et al, 1998), improves sociality. On the other hand, the typical antipsychotic drug, haloperidol, is inactive (Sams-Dodd, 1997; Qiao et al, 2001, Mohn et al, 1999). Clozapine, but not haloperidol, also reverses other behaviors induced by chronic PCP administration (Noda et al, 1995).

Although the mechanism by which PCP alters social behavior is unclear, there are relatively few endogenous substances that could serve as central mediators of social behaviors in rodents. Two primary targets worth examining for central changes leading to social behavioral deficits are the neuropeptides oxytocin (OT) and arginine vasopressin (AVP), as well as their cognate central receptors (for a review see, Insel and Young, 2000; Ferguson et al, 2002).
Despite an abundance of AVP and OT in the brain, there is a paucity of investigations of OT and AVP in the schizophrenia literature, and the majority of the reports employ indirect cerebrospinal fluid (CSF) measures that may or may not reflect brain tissue levels. However, there are several reports of central dysregulation of one or both of these neuropeptides in the context of schizophrenia. Linkowski et al (1984) reported decreased neurophysin I (a putative marker for OT) and increased levels of neurophysin II (a marker for AVP) in the CSF of schizophrenic patients as compared to control levels; a difference has also been seen in neurophysin I and II immunoreactivity within the paraventricular nucleus of the hypothalamus (PVN) and in the nucleus accumbens (Mai et al, 1993). Legros et al (1992) found that in schizophrenic patients, apomorphine, a dopamine receptor agonist, failed to evoke any change in serum levels of either neurophysin, as opposed to control subjects who responded to an apomorphine challenge with significant increases in circulating levels of both neuropeptide-related cleavage products. The authors also noted that schizophrenic patients had a significant difference from control subjects at baseline in serum levels of neurophysin I (decreased) and neurophysin II (increased). The failure of dopamine agonism to increase the secretion of peripheral neurophysins could reflect dopamine receptor desensititzation in the peripheral AVP and OT systems due to the hypothesized hyperdopaminergia inherent to schizophrenia (Legros et al, 1992). However, studies of CSF and peripheral AVP (Beckmann et al, 1985; Elman et al, 2003; Raskind et al, 1987) and CSF OT (Glovinsky et al, 1994) concentrations have failed to reveal consistent baseline differences in these peptides between schizophrenic and control volunteers. Bernstein et al (1998, 2000) examined hypothalamic tissue taken from patients diagnosed with schizophrenia and found a significant decrease in nitric oxide synthase immunopositive neurons within the PVN but not in the supraoptic nucleus (SON) relative to control patients. While Bernstein et al (1998, 2000) did note fewer cells with staining in the SON, it is unclear whether these neurons contained AVP or OT. A post-mortem study of tissue AVP concentrations found decreased AVP amounts in the temporal lobe of schizophrenic brain tissue, but the hypothalamic content was not different from controls (Frederiksen et al, 1991). AVP analogues have been shown to be effective adjunctive treatments of schizophrenic symptoms, particularly negative spectrum symptoms (Brambilla et al, 1986, 1989; Iager et $a l, 1986)$, and poorly controlled trials reporting psychotic symptom improvement after OT administration also exist (Bujanow, 1974).

Neuropeptide changes may also underlie some altered behaviors in animal models of schizophrenia. Tanaka et al (2003) have reported that chronic PCP administration causes a reduction in $\mathrm{V} 1 \mathrm{aR}$ binding in the lateral septum (LS), substantia nigra, bed nucleus of the stria terminalis, and other regions. In rats, subcutaneous administration of OT dose dependently normalized reductions in prepulse inhibition (PPI) of the startle response caused by amphetamine or an NMDA receptor antagonist (Feifel and Reza, 1999). Measurement of PPI has proven to be a valuable translational tool as such deficits are present in both schizophrenic patients (Braff and Geyer, 1990; Swerdlow 
et al, 1994) and in rat models of schizophrenia generated using dopamine agonists (Swerdlow et al, 1992), noncompetitive NMDA receptor antagonists (Mansbach and Geyer, 1989), early life isolation rearing (Varty and Geyer, 1998), and prenatal stress (Koenig et al, 2005). Brattleboro rats, a rat naturally lacking the ability to synthesize functional AVP, also exhibit PPI deficits (Feifel and Priebe, 2001). Thus, the successful treatment of sensorimotor gating disturbances with a neuropeptide along with the V1aR binding results of Tanaka et al (2003) are significant because they reaffirm the distinct possibility that, in animal models of schizophrenia, neuropeptides are altered by many different pharmacological and experiential manipulations purported to model schizophrenogenic insults. Furthermore, it predicts the potential efficacy of central-acting AVP or OT analogues as potential schizophrenia treatments. In the current work, the expression of mRNA and receptor binding of OT and AVP are used to describe the interplay of NMDA receptor markers with changes in vasopressinergic and oxytocinergic tone in the chronic PCP animal model of schizophrenia. Animals treated repeatedly with PCP also exhibit abnormalities in social behavior, which may be a useful marker for some aspects of the negative symptoms of schizophrenia (Sams-Dodd, 1997; Qiao et al, 2001) and allow evaluation of the efficacy of both OT and AVP to resolve this behavioral deficit. These results highlight how selective changes in neuropeptidergic systems may represent a possible novel pathological change in the schizophrenic brain.

\section{MATERIALS AND METHODS}

\section{Animals}

Male Sprague-Dawley rats were purchased from Charles River Laboratories (Wilmington, MA). All rats were maintained in facilities fully accredited by the American Association for the Accreditation of Laboratory Animal Care (AAALAC) on a $12 \mathrm{~h}$ light/dark schedule (lights on: 0700) with ad libitum access to food and water throughout the duration of the experiment (except as noted). The treatment of these rats was in accordance with the National Institutes of Health (NIH) guidelines for animal research, and all procedures were approved by the University of Maryland School of Medicine Institutional Animal Care and Use Committee.

Chronic PCP administration paradigm. This procedure was adapted from Sams-Dodd (1995). Male Sprague-Dawley rats (initial weight: $175-200 \mathrm{~g}$ ) were housed two-three/cage and maintained as stated above. Following random assignment to condition, rats received injections (i.p.) of either sterile $0.9 \%$ saline vehicle (chronic saline control) or an appropriate volume of $3.0 \mathrm{mg} / \mathrm{kg}$ PCP (Sigma, St Louis, MO) dissolved in sterile saline. All rats housed together in the same cage received the same treatment. Injections were administered once daily for 14 days at random times between 0900 and 1500 .

Cannulation of brain nuclei. Cannulae directed toward the central nucleus of the amygdala were implanted into the brain of anesthetized male rats using a stereotaxic apparatus
(David Kopf, Inc.). Holes in the skull over the central nucleus of the amygdala were created using a dental drill. Guide cannulae (Plastics One, Inc., Roanoke, VA), constructed of 22-gauge stainless-steel tubing, were placed bilaterally above the central amygdaloid nucleus using coordinates from Paxinos and Watson (1986) (AP: $-2.3 \mathrm{~mm}$ relative to bregma, L: $\pm 4.1 \mathrm{~mm}, \mathrm{DV}:-7.0 \mathrm{~mm}$, Plate 27 ). The guide cannulae were fixed to the rat's skull using four self-tapping stainless-steel screws and acrylic dental cement (Lang Dental, Wheeling, IL). The cannulae were capped with an obdurator constructed from 28-gauge stainless-steel wire. Following a 7-day period of recuperation, all animals were weighed. Animals that had regained their presurgical body weight were used as experimental subjects. Rats failing to regain their body weight during the 7 days after surgery were excluded from experimental use. The cannulated animals were divided into two groups. One group received a daily injection of PCP $(3 \mathrm{mg} / \mathrm{kg}$, i.p. $)$ and the other group received a daily injection of saline (i.p.). The rats were treated with PCP or saline for 14 days as described above. As a part of the injection routine, the obdurators were removed from the guide cannulae to acclimate animals to the manipulation of the cannulae that would occur during the testing phase of the studies. Cannulae positions were histologically verified for all animals following behavioral testing using cresyl violet stained sections and in some cases, $\left[{ }^{125} \mathrm{I}\right]$ oxytocin receptor antagonist (Amersham Bioscience, Pistcataway, NJ) was microinjected and autoradiographic images were compared with cresyl violet stained sections.

\section{Behavioral Tests}

Social interaction test. The social interaction procedure was adapted from that of File and Hyde (1979). On each of the 2 days prior to testing, experimental rats (rats treated with chronic PCP or chronic saline) or their weightmatched male target rats were weighed and placed into a black plexiglass arena (dimensions: $65 \mathrm{~cm}$ length $\times 65 \mathrm{~cm}$ width $\times 47 \mathrm{~cm}$ height) individually for $10 \mathrm{~min}$ in order to acclimate to the novel setting under moderately bright lighting (150lux). The bottom of the arena was lined with absorbent bedding. In chronic PCP- and chronic salinetreated rats, the acclimation sessions began $24 \mathrm{~h}$ after the final (ie 14th) i.p. injection was administered. When applicable, acclimation and interaction testing was initiated 21 days after the surgical placement of the amygdalar cannulae to permit full recovery.

On the day of testing, rats with amygdalar cannulae received bilateral intracranial infusions as described above and were placed immediately into the arena alone for $10 \mathrm{~min}$ using the same lighting conditions as during training. This portion of the test was videotaped and digitally analyzed later using a Noldus Ethovision apparatus (Noldus Information Technology, Inc., Leesburg, VA) to evaluate open field ambulatory behaviors (total locomotor distance and total center distance traveled). When this 10min session expired, a weight-matched male target rat was introduced into the arena. This social interaction trial lasted 10 min. Experimental and target rats were not used in this paradigm more than one time. The arena was cleaned with $70 \%$ ethanol between each trial. All sessions were video- 
taped using a cordless video camera so the experimenter could remain outside the room while monitoring the entire testing session. Later, videotapes were scored in a blinded fashion for the time the experimental rat actively engaged in social interaction behaviors (eg sniffing, grooming, following, crawling over/under, or boxing/wrestling) with the target male.

Further analysis was performed on the videotapes to assess the relative amounts of time experimental rats engaged in contact or noncontact social interaction with their novel peers. Contact behaviors were defined as behaviors requiring obligate physical contact; anogenital exploration, sniffing with direct contact, crawling, grooming, and play behaviors met this criterion. Following and proximal (no contact) sniffing were considered noncontact social interactions and scored as such.

Open field testing. The open field activity of chronic PCPtreated or chronic saline-treated male rats were performed under moderately bright light conditions (150lux) from 1200 to $1600 \mathrm{~h}$. Activity was analyzed using a Noldus Ethovision apparatus (Noldus Information Technology, Inc., Leesburg, VA) from the videotape of 10-min sessions when the animal was alone and exploring the social interaction arena during the first acclimation session. Measures of peripheral and central locomotion were obtained. The center of the box was defined as a square measuring $35 \mathrm{~cm}$ long $\times 35 \mathrm{~cm}$ wide offset $15 \mathrm{~cm}$ from the outer perimeter of the social interaction arena.

The open field activities of experimental rats infused with OT (1000 ng) or saline vehicle were analyzed using a Noldus Ethovision apparatus (Noldus Information Technology, Inc., Leesburg, VA) from the videotapes of 10-min sessions when the animal was alone and exploring the social interaction arena immediately prior to social interaction testing. Measures of peripheral and central locomotion were obtained. The center of the box was defined as a square measuring $35 \mathrm{~cm}$ long $\times 35 \mathrm{~cm}$ wide offset $15 \mathrm{~cm}$ from the outer perimeter of the social interaction arena.

Light-dark emergence test. This procedure was adapted from that of Gurtman et al (2002). Male rats were placed inside of a familiar black cylindrical tube (dimensions: $19 \mathrm{~cm}$ length $\times 7.5 \mathrm{~cm}$ diameter, light level 3 lux) open at one end. The tube was positioned such that the opening faced the upper left corner of an open field (which was the same arena used in social interaction testing, light level 150 lux). The rats' behaviors were videotaped for $5 \mathrm{~min}$ while the experimenter was outside the room. The arena and tube were cleaned with a $70 \%$ ethanol after each trial. The latency to emerge and times spent inside and outside the tube were scored from the videotape in a blinded fashion. This test was performed prior to social interaction testing so that rats were naïve to the arena. Testing took place between 1200 and $1600 \mathrm{~h}$.

\section{Analytical Protocols}

OT and AVP MRNA in situ hybridization histochemistry. These methods have been previously published (Lee et al, 2003). Rats designated for use in these biochemical studies were killed by decapitation $24 \mathrm{~h}$ after social interaction testing. Their brains were removed rapidly, placed into powdered dry ice with the hypothalamus facing upwards, and stored at $-70^{\circ} \mathrm{C}$ until sectioning into coronal brain sections $(12 \mu \mathrm{m}$ thickness) using a cryostat. These sections were mounted consecutively on SupraFrost Plus slides (Fisher Scientific) and stored at $-70^{\circ} \mathrm{C}$ until thawing immediately prior to use. Every ninth section was mounted separately and stained with cresyl violet for anatomical verification. Sections from all similar experimental groups and their controls were run in the same in situ hybridization experiment. Thawed sections from subjects in all experimental groups were fixed in $4 \%$ paraformaldehyde, then acetylated with acetic anhydride $(0.25 \%)$ in triethanolamine $(0.1 \mathrm{M}, \mathrm{pH} 8)$, and finally were dehydrated through graded alcohols and delipidated in chloroform. The sections were coated with a hybridization buffer containing 50\% formamide, $2 \times$ SSC, $10 \%$ dextran sulfate, $0.25 \%$ BSA, $0.25 \%$ polyvinylpyrrolidone, $0.25 \%$ Ficoll $400,250 \mathrm{mM}$ Tris $(\mathrm{pH}$ 7.5), $0.5 \%$ SDS, $250 \mu \mathrm{g} / \mathrm{ml}$ single-stranded salmon sperm DNA containing $1 \times 10^{6} \mathrm{cpm}$ of the appropriate ${ }^{35} \mathrm{~S}$-labeled cRNA probe (see below). Following hybridization ( $14 \mathrm{~h}$ at $55^{\circ} \mathrm{C}$ in a humid chamber), the slides are washed in $4 \times$ $\mathrm{SSC}$, incubated with RNase A $(20 \mathrm{mg} / \mathrm{ml})$ to reduce background, washed under high stringency conditions $(0.1 \times$ SSC at $68^{\circ} \mathrm{C}$ ), and dehydrated in graded ethanol solutions $(70-100 \%)$. After the slides had dried for a minimum of $2 \mathrm{~h}$, they were placed alongside calibrated ${ }^{14} \mathrm{C}$ microscales (Amersham Pharmacia Biotech, Piscataway, NJ) into X-ray cassettes with Kodax BioMax MR film. Optimal exposure times were determined empirically for each probe (see below). The films were developed according to the manufacturer's protocol.

Descriptions of $m R N A$ probes. Bacterial plasmid vectors containing DNA inserts encoding OT and AVP sequences were obtained from Thomas Sherman, PhD (Georgetown University, Washington, DC; Sherman et al, 1988). OTR mRNA studies in $\mathrm{CeA}$ and ventromedial hypothalamus (VMH) were performed using a probe obtained from $\mathrm{Dr}$ Daniel Dorsa (Oregon Health Sciences University, Portland, Oregon); this OTR as well as the V1aR template have been described elsewhere (Bale et al, 1995; Szot et al, 1994). Sense cRNA sequences were also generated from these plasmids and each was tested in rat brain tissue (not shown). Exposure times were based on the radioactivity content of the applied probes (OT mRNA: $24 \mathrm{~h}$; AVP mRNA: $45 \mathrm{~min}$; OTR mRNA: 14-15 days; V1aR mRNA: 10 days).

$O T$ and AVP receptor binding autoradiography. This procedure was adapted from methods described elsewhere (Francis et al, 2002). Fresh-frozen rat brain tissue sections prepared identically to those used in the in situ hybridization histochemical studies described above were used. Slides were thawed at room temperature for $10 \mathrm{~min}$; a Pap pen (Sigma-Aldrich, St Louis, MO, USA) was used to encircle the outer perimeter of the tissue sections. Next, the tissue was fixed in $4 \%$ paraformaldehyde for $2 \mathrm{~min}$ and rinsed in three washes of $50 \mathrm{mM}$ Tris-buffered saline (TBS, $\mathrm{pH}$ 7.4) for $5 \mathrm{~min}$ at room temperature. Immediately following the third wash, tissue sections were incubated for $1 \mathrm{~h}$ with a $500 \mu \mathrm{l}$ 
aliquot of TBS containing $10 \mathrm{mM} \mathrm{MgCl}_{2}, 0.1 \%$ bovine serum albumin, $0.05 \%$ bacitracin, and $50 \mathrm{pM}$ of the $\left[{ }^{125} \mathrm{I}\right]$ receptor-specific ligand. For OTR binding, the ligand was $\left[{ }^{125} \mathrm{I}\right] \mathrm{d}\left(\mathrm{CH}_{2}\right)_{5}\left[\mathrm{Tyr}(\mathrm{Me})_{2}, \mathrm{Thr}^{4}, \mathrm{Orn}^{8}, \mathrm{Tyr}^{9}-\mathrm{NH}_{2}\right]$-vasotocin (OVTA, $2200 \mathrm{Ci} / \mathrm{mmol}$, Amersham Bioscience, Piscataway, $\mathrm{NJ})$; for V1a receptor the ligand was ${ }^{125}$ I-labelled linvasopressin $(2200 \mathrm{Ci} / \mathrm{mmol}$, Amersham Bioscience, Piscataway, NJ). Nonspecific binding was determined by adding $50 \mathrm{mM}$ unlabeled $\mathrm{Thr}^{4}, \mathrm{Gly}^{7}$ oxytocin or [1-( $\beta$-mercapto$\beta, \beta$-cyclo-pentamethylene propionic acid),2-(O-methyl)tyrosine]-arg8-vasopressin (Bachem, San Carlos, CA) to the incubation mixture. After incubation, slides were rinsed in four cold $\left(4^{\circ} \mathrm{C}\right) 50 \mathrm{mM}$ TBS washes containing $10 \mathrm{mM}$ $\mathrm{MgCl}_{2}$ for $5 \mathrm{~min}$ followed by a fifth wash in the same chilled buffer for $30 \mathrm{~min}$. Finally, slides were rapidly dried under a stream of cool air. When slides were dry, they were placed into autoradiographic cassettes with Kodax BioMax MR film. $\left[{ }^{125} \mathrm{I}\right]$ microscale standards (Amersham Biosciences, Piscataway, NJ) were placed into all X-ray cassettes. Film was developed after 6-7 days of exposure.

Data analysis. The atlas of Paxinos and Watson (1986) was used to define the locations and boundaries of the brain structures of interest (CeA, VMH, LS, and PVN) on cresyl violet stained sections taken at approximately $100 \mu \mathrm{m}$ intervals from each brain. Densitometric analyses were performed on the autoradiographic films using NIH Image software (version 1.62) running on a Power Macintosh computer. Measurements were obtained in at least three consecutive tissue sections (except PVN, which was performed on at least two consecutive sections) containing the desired structure. For in situ hybridization histochemistry, background levels of hybridization were obtained from readings in white matter structures such as the corpus callosum, where minimal binding would be expected to occur and subtracted from the mean reading of the area of interest using the semiquantitation methodology of Bowers et al (1998). For receptor binding, the amount of radioactivity within the tissue sections (as a $\mathrm{dpm} / \mathrm{mg}$ equivalent) was determined by creating a best-fit curve (a Rodbard fit) to the image of the known $\left[{ }^{125} \mathrm{I}\right]$ microscale standard. Nonspecific binding in an adjacent section was subtracted from the final estimate of bound ligand to determine the specific tissue binding.

\section{Statistical Analysis}

Data from the social interaction and light-dark emergence tests are reported as mean time in seconds \pm standard error of the mean (SEM) or as percent of total interaction time \pm SEM. Open field data are reported as mean total cumulative distances (in $\mathrm{cm}$ ) \pm SEM. Statistical significance for social interaction comparisons between chronic PCP and chronic saline was determined by an independent sample $t$-test using GraphPad Prism 4.0 software (San Diego, CA). A repeated measures ANOVA was used to analyze the contact $v s$ noncontact comparisons, light-dark emergence data, and locomotor behaviors of experimental rats and their matched controls. Post hoc analysis using the Bonferroni test was conducted where appropriate to compare individual group means.
The in situ hybridization histochemistry data are reported as the mean percent of the appropriate control subjects' relative optical density readings \pm SEM. Receptor binding data are expressed as the mean percent of control radioactive ligand content \pm SEM. Optical density readings of mRNA and receptor binding present in appropriate control tissue samples were established as $100 \%$ for purposes of relative comparison. Statistical significance for mRNA expression and receptor binding was determined by an independent sample $t$-test using GraphPad Prism 4.0 software (San Diego, CA). In all instances, a $p$-value $<0.05$ was considered significant.

\section{RESULTS}

\section{Behavioral Changes Induced by PCP}

Social interaction after chronic PCP administration (Figures 1 and 2). As in other studies (Sams-Dodd, 1995), 2 weeks of treatment with a low dose of PCP significantly reduced ( $t$-test, $t=9.06 ; \mathrm{df}=14 ; p<0.0001$; Figure 1 ) the cumulative time spent in social interaction relative to chronic saline-treated rats. Chronic PCP treatment reduced social interaction by approximately $73 \%$ as compared to chronic saline treated rats' mean time of interaction. Prolonged ( $>5 \mathrm{~s})$ freezing indicative of an acute fear response was not observed in any experimental subject nor were incidents of overtly aggressive actions (eg biting to injury) by any experimental or target animal.

A breakdown of the scored behaviors expressed as a percentage of the total interaction time revealed a significant qualitative difference in how rats from the two treatment groups behaved with a novel male target. Specifically, the behaviors of rats treated with chronic PCP shifted from contact social interaction (predominantly anogenital exploration and crawling over/under) to noncontact social interaction (following). A repeated measures ANOVA performed on the behavioral data from chronic PCP-treated rats revealed a significant main effect for behavior $\left(\mathrm{F}_{(1,14)}=61.2, p<0.0001\right.$; Figure 2$)$ and a significant interaction of drug treatment with behavior

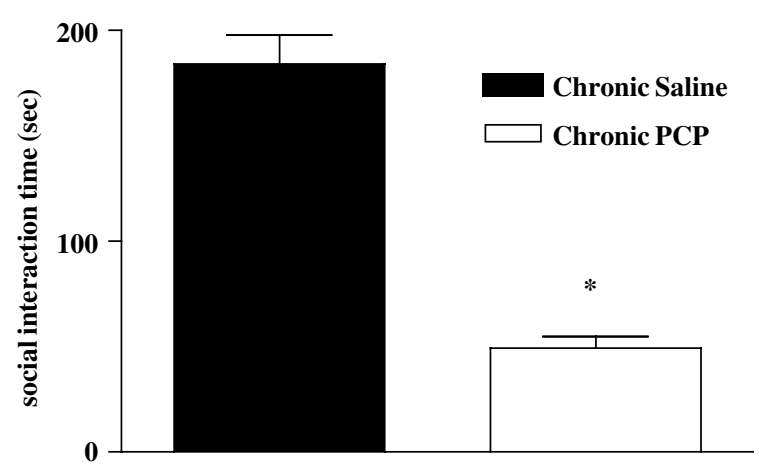

Figure I Social interaction behaviors after chronic PCP administration. Two weeks daily injections of $3 \mathrm{mg} / \mathrm{kg}$ PCP significantly reduced $(* p<0.000 \mathrm{I}, n=8)$ the mean cumulative amount of time male rats engaged in social behaviors with novel target males when compared to the mean time rats treated with saline vehicle (chronic saline, $n=8$ ) interacted with target males. Data shown are mean total social interaction times \pm SEM for each group. 
$\left(\mathrm{F}_{(2,14)}=35.1, p<0.0001\right)$. Male rats following chronic PCP administration spent a significantly larger fraction of their total social interaction $(82 \pm 2 \%)$ engaged in noncontact interaction with the target rat compared to the percentages of chronic saline-treated rats $(53 \pm 5 \%)$. In contrast, chronic saline-treated males spent a greater proportion of their total social interaction time $(44 \pm 4 \%)$ engaged in social interactions requiring physical contact than their chronic PCPtreated peers.

Open field locomotion after chronic PCP administration (Table 1). As others have noted (Hanania et al, 1999), chronic PCP treatment followed by withdrawal was not associated with an increase in total distance traveled nor in distance traveled in the center of the arena (repeated measures ANOVA, $\left.F_{(1,12)}=0.007, p>0.05\right)$ in an unfamiliar open field arena.

Light-dark emergence after chronic PCP administration. In a light-dark emergence test, all subjects emerged from the enclosure within the first $30 \mathrm{~s}$ of the test. Following chronic PCP $(n=5)$ or chronic saline treatments $(n=5)$, the mean latencies to emerge were $2.2 \pm 1$ and $2.4 \pm 0.7 \mathrm{~s}$; the mean times spent outside the enclosure were $289.8 \pm 4.4 \mathrm{~s}$

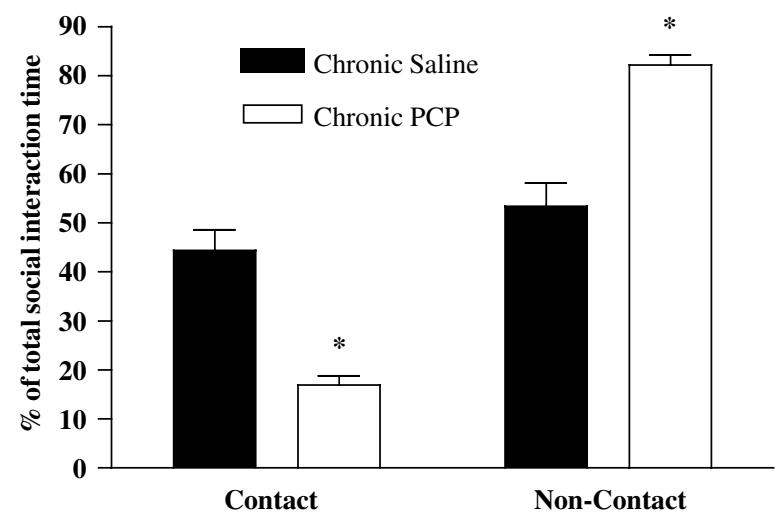

Figure 2 Comparison of contact and noncontact social interaction in a rat model of schizophrenia. After administration of chronic PCP, adult male rats ( $n=8$ /group) spent a significantly larger percentage $(* p<0.000$ I $)$ of their social interaction time engaged in a noncontact behavior (following) with a male target as opposed to behaviors with obligate close physical proximity (anogenital exploration or crawling over/under). The distribution of behavioral percentages for chronic saline-treated rats $(n=8)$ revealed a significantly greater $(* p<0.000 I)$ preference for contact behaviors. Data shown are mean percent of total time spent engaged in social interaction \pm SEM

Table I Open Field Locomotor Behavior of Male SpragueDawley Rats Treated with Chronic PCP

\begin{tabular}{lcc}
\hline & $\begin{array}{c}\text { Total peripheral } \\
\text { distance traveled } \\
\mathbf{( c m})\end{array}$ & $\begin{array}{c}\text { Total center } \\
\text { distance traveled } \\
\mathbf{( c m )}\end{array}$ \\
\hline Chronic saline $(n=8)$ & $988 \pm 375$ & $306 \pm 90$ \\
Chronic PCP $(n=8)$ & $1027 \pm 442$ & $315 \pm 86$ \\
\hline
\end{tabular}

Data are means \pm SEM. for chronic PCP-treated rats and $294.8 \pm 1.8 \mathrm{~s}$ for chronic saline-treated rats. A repeated measures ANOVA performed on these data revealed that there was no effect attributable to drug treatment when chronic PCP-treated rats were compared to chronic saline-treated rats $\left(\mathrm{F}_{(1,16)}=0.95, p>0.05\right)$.

\section{Oxytocinergic and Vasopressinergic Marker mRNA Expression in PCP-Treated Rats}

OT and OTR $m R N A$ expression. OT mRNA expression was evaluated in the PVN of chronic saline- and chronic PCPtreated rats using in situ hybridization histochemistry. OT mRNA expression in the PVN was reduced over $30 \% 72 \mathrm{~h}$ after the cessation of chronic PCP administration compared to rats injected with saline for 2 weeks ( $t$-test, $t=4.32$, $\mathrm{df}=14, p<0.001$; Table 2, Figure $3 \mathrm{a}$ and $\mathrm{b}$ ). OTR mRNA expression was also examined in the CeA and VMH. No significant differences in OTR mRNA expression levels were noted following PCP treatment in either of these brain regions (Table 2).

AVP and V1aR mRNA expression. AVP mRNA was evaluated in the PVN and SON of rats treated with chronic PCP. No significant changes were noted in AVP mRNA expression in either the PVN or the SON following chronic PCP or chronic saline treatment (Table 2). Similarly, V1aR mRNA expression was found to be unchanged in the CeA following chronic PCP treatment compared to saline-treated controls (Table 2).

\section{Neuropeptide Receptor Autoradiography}

OTR and V1aR binding autoradiography. Binding of a radiolabeled OTR-specific ligand in the CeA was signifi-

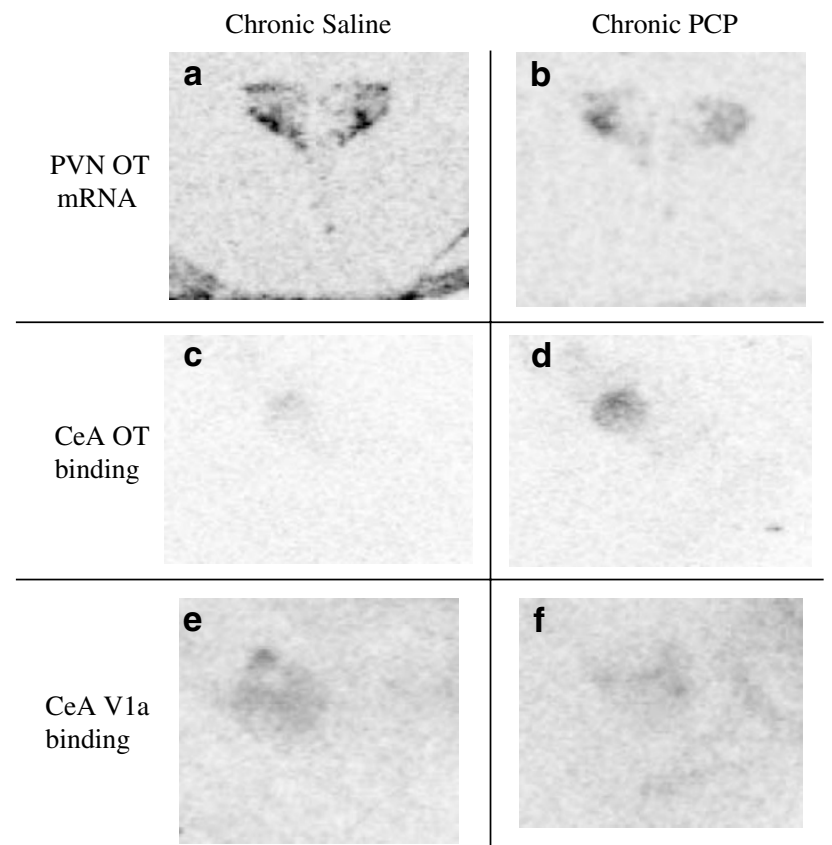

Figure 3 Representative film autoradiographic images of the expression of OT mRNA in the PVN, binding of OT in the CeA and binding of a VIa specific ligand in the CeA of chronic saline treated (panels a, $c$ and e) or chronic PCP treated (Panels b, d, and f) rats. 
Table 2 OT, AVP, OTR, or VIaR mRNA Expression (Percent of Chronic Saline Expression) Within Distinct Brain Regions in Male Sprague-Dawley Rats Treated with Chronic PCP or Chronic Saline For 2 Weeks

\begin{tabular}{lccc}
\hline mRNA probe & Region & $\begin{array}{c}\text { Chronic saline } \\
(\mathbf{n}=\mathbf{8})\end{array}$ & $\begin{array}{c}\text { Chronic PCP } \\
(\mathbf{n}=\mathbf{8})\end{array}$ \\
\hline AVP & PVN & $100 \pm 4 \%$ & $94 \pm 7 \%$ \\
& SON & $100 \pm 6 \%$ & $103 \pm 4 \%$ \\
OT & PVN & $100 \pm 4 \%$ & $69 \pm 6 \% * *$ \\
VIaR & CeA & $100 \pm 3 \%$ & $108 \pm 7 \%$ \\
OTR & & & \\
& CeA & $100 \pm 5 \%$ & $94 \pm 7 \%$ \\
\hline
\end{tabular}

Data are mean percents \pm SEM.

*** $p<0.000$ I.

cantly increased by 2 weeks of daily PCP treatment $(194 \pm 13 \%$ relative to chronic saline treatment, $t$-test, $t=2.49, \mathrm{df}=12, p<0.03$; Figure $3 \mathrm{c}$ and $\mathrm{d})$. No difference in OTR binding was found in the LS of rats in the chronic PCP model rats $(97 \pm 4 \%$ of chronic saline-treated control rats, $t=0.78, \mathrm{df}=14, p>0.05)$. OTR binding within the VMN was also unchanged following chronic PCP treatment $(112 \pm 8 \%$ of chronic saline-treated rats, $t$-test, $t=1.27$, $\mathrm{df}=14, p>0.05)$.

V1aR binding was decreased in the CeA of rats treated with chronic PCP relative to those treated with saline for 2 weeks (Figure $3 \mathrm{~d}$ and e). There was a significant decrease of approximately $20 \%$ in $\mathrm{V} 1 \mathrm{aR}$ binding in the $\mathrm{CeA}$ after chronic PCP treatment ( $t$-test, $t=4.00, \mathrm{df}=9, p<0.003$ ). As first reported by Tanaka et al (2003), following chronic PCP treatment, the binding of the V1aR specific ligand in LS was decreased by $58 \%$ following chronic PCP treatment ( $t$-test, $t=4.03, \mathrm{df}=12, p<0.002)$.

\section{OT-Induced Behavioral Changes}

Social interaction after chronic PCP administration followed by intra-amygdalar neuropeptide infusions (Figures 4-6). Given the deficit in social behavior identified in the chronic PCP-treated rats and the alterations in oxytocinergic markers, additional studies were undertaken to determine whether exogenous administration of oxytocin would improve behavior in chronic PCP-treated male rats. A two-way ANOVA revealed a significant effect of chronic PCP treatment $\left(\mathrm{F}_{(1,46)}=81.3, p<0.0001\right.$; Figure 4$)$ on social interaction. As in previous experiments (see above), 2 weeks of daily treatment with low-dose PCP was associated with a significant decrease in social interaction relative to the interaction of rats receiving chronic saline treatments; the magnitude of this decrease, approximately $76 \%$ of chronic saline-treated rats in this study (as compared to approximately $73 \%$ in previously described chronic PCP experimental results), was not altered by infusions of saline into the CeA. The two-way ANOVA also revealed a significant effect of infusion $\left(\mathrm{F}_{(5,46)}=5.60, p=0.0004\right)$ and a significant

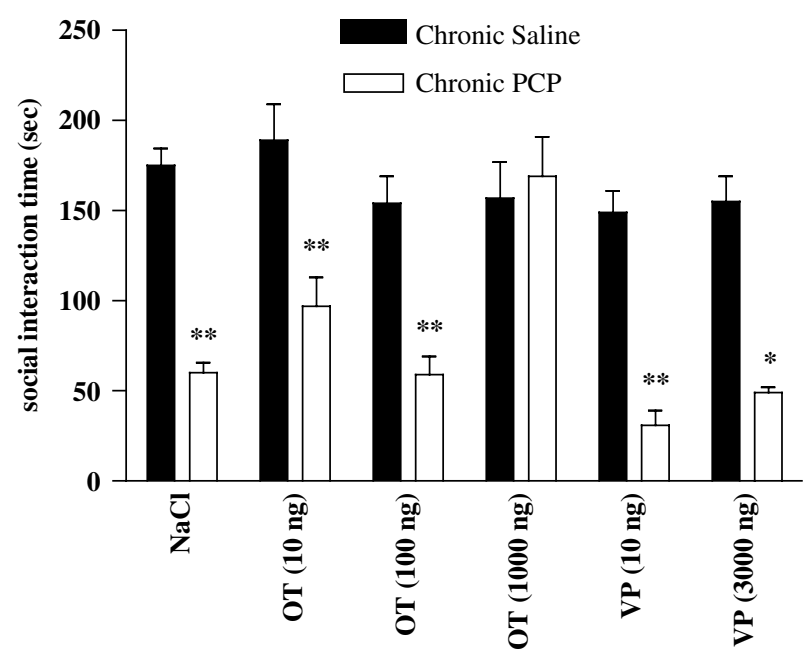

Bilateral CeA Infusion

Figure 4 Cumulative mean time spent engaged in social interaction behavior by chronic saline-treated and chronic PCP-treated male rats after infusions into the CeA of VP, OT, and saline (vehicle). All social interaction mean times were compared to chronic saline-treated rats infused with the same ligand ( $n=3-6 /$ group). OT infusions ( $1000 \mathrm{ng}$ ) into chronic salinetreated male rats $(n=6)$ had no effect on social interaction. Bilateral infusions of 1000 ng of OT into chronic PCP-treated rats $(n=6)$ increased social interaction to a level identical to that of control rats infused with saline or OT. Infusions rats of two lower doses of OT, I00 ng $(n=6)$ and $10 \mathrm{ng}(n=5)$ into chronic PCP-treated were associated with the same significant $(* * * 0.001)$ reduction in social interaction found in salineinfused, chronic PCP treated rats $(n=6)$. Two infused doses of VP, $10 \mathrm{ng}$ $(n=6)$ and $3000 \mathrm{ng}(n=3)(* p<0.01)$, were also unable to restore normal levels of social interaction in chronic PCP-treated rats. Data are shown as the mean total social interaction times \pm SEM.

interaction between $\mathrm{PCP}$ treatment and infusion $\left(\mathrm{F}_{(5,46)}=4.43, p=0.0022\right)$. A post hoc Bonferroni test comparing all mean cumulative social interaction times revealed that the mean social interaction times of chronic PCP-treated rats following infusions of saline $(p<0.001)$, $10 \mathrm{ng}$ of OT $(p<0.001), 100 \mathrm{ng}$ of OT $(p<0.001), 10 \mathrm{ng}$ of AVP $(p<0.001)$, or $3000 \mathrm{ng}$ of AVP $(p<0.01)$ were significantly lower than the cumulative mean time of chronic saline-treated rats infused with the same ligands. The cumulative social interaction times of chronic salinetreated rats infused with any dose of OT or either dose of AVP and the cumulative mean time of chronic PCP-treated rats infused with $1000 \mathrm{ng}$ of OT were not significantly different $(p>0.05)$ than the mean time of chronic salinetreated, saline-infused rats. The infused peptide's effects were limited to the CeA because autoradiographic images show that the spread of $\left[{ }^{125} \mathrm{I}\right]$ OVTA following microinjection through the implanted cannulae is restricted to the CeA as shown in Figure 5.

Previous investigations of chronic PCP's effects (see above) on social interaction had demonstrated decreased time spent engaged in social interaction as well as a shift from contact to noncontact interactive behaviors. The proportionate time infused rats from the chronic PCP paradigm engaged in contact and noncontact behaviors was evaluated to ascertain whether the successful restoration of cumulative time noted at the $1000 \mathrm{ng}$ dose of OT heralded a parallel normalization of interest in physical contact with a male peer. 


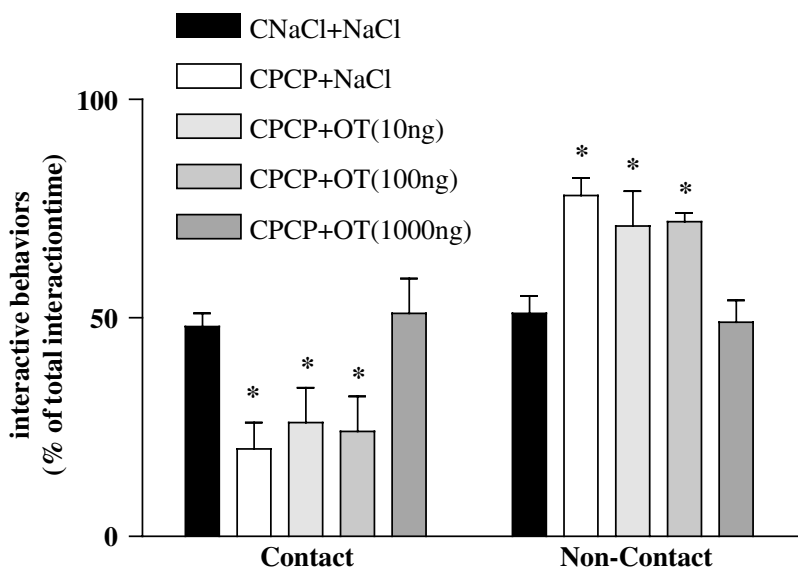

Figure 6 Contact and noncontact behaviors after OT or saline infusions into the CeA of chronic PCP-treated or chronic saline-treated male rats expressed as a percentage of total social interaction time. The mean percents of contact and noncontact behaviors were compared to those of saline-treated, saline-infused control rats $(n=8)$. Bilateral infusions of 1000 ng of OT into chronic PCP-treated rats $(n=6)$ increased contact behaviors (sniffing, crawling over/under) to a level identical to that of control rats infused with saline. Two other infused doses of OT, $100 \mathrm{ng}$ $(n=6)$ and $10 \mathrm{ng}(n=5)$ were associated with the same significant $(* p<0.01)$ reduction in contact interactions found in saline-infused, chronic PCP treated rats $(n=6)$. Data are shown as the mean percent of total social interaction time \pm SEM.

Table 3 Open Field Locomotor Behavior of Sprague-Dawley Male Rats Treated with Chronic PCP after Infusions of OT or Saline into the CeA

\begin{tabular}{llcc}
\hline & Infusion & $\begin{array}{c}\text { Total distance } \\
\text { traveled }\end{array}$ & $\begin{array}{c}\text { Total center } \\
\text { distance }\end{array}$ \\
\hline Chronic saline & $\mathrm{NaCl}$ & $1211 \pm 245$ & $380 \pm 22$ \\
& OT & $1267 \pm 236$ & $342 \pm 33$ \\
Chronic PCP & $\mathrm{NaCl}$ & $1444 \pm 65$ & $230 \pm 120$ \\
& OT & $1417 \pm 386$ & $355 \pm 25$ \\
\hline
\end{tabular}

A two-way ANOVA confirmed a significant interaction between drug treatment and peptide infusion $\left(\mathrm{F}_{(4,24)}=12.0\right.$, $p<0.001$; Figure 6). Post hoc analysis revealed that the previously observed shift from contact to noncontact behaviors was still present in chronic PCP-treated rats infused with saline as they spent a higher percentage of their interaction engaged in noncontact behaviors (Bonferroni, $p<0.01)$. The two infused doses of OT that failed to elevate social interaction (10 and $100 \mathrm{ng}$ ) also failed to rectify the shift to more noncontact interactive behaviors in chronic PCP-treated animals (Bonferroni, $p<0.01$ ). However, the $1000 \mathrm{ng}$ dose of infused OT restored the balance between contact and noncontact behaviors in chronic PCP-treated male rats to levels similar to those of chronic saline-treated, saline infused subjects (Bonferroni, $p>0.05$ ).

Open field locomotion after chronic PCP administration followed by intra-amygdalar neuropeptide infusions (Table 3). The highest effective intracranial infusion dose of OT (1000 ng) did not alter the ambulatory behavior of chronic PCP model rats relative to appropriate salineinfused control subjects. The total distance traveled did not differ (repeated measures ANOVA, $\mathrm{F}_{(3,11)}=0.19, p>0.05$ )

Data are mean distance $(\mathrm{cm}) \pm \mathrm{SEM}$.

between chronic PCP-treated rats (infused with saline or $1000 \mathrm{ng}$ OT) and chronic saline-treated rats (infused with saline or $1000 \mathrm{ng}$ OT). These groups also did not differ in the total ambulatory distance traveled within the center of the open field $\left(\mathrm{F}_{(3,11)}=0.41, p>0.05\right)$. Saline-infused chronic PCP-treated and chronic saline-treated male rats also did not differ in the total ambulatory distance traveled within the center of the open field $\left(\mathrm{F}_{(3,11)}=0.25, p>0.05\right)$.

\section{DISCUSSION}

Bilateral infusion of $1000 \mathrm{ng}$ of OT into the CeA following 2 weeks of low-dose PCP treatment selectively normalized the time male rats spent engaged in social interaction and increased the proportion of time these rats spent engaged in 
proximal contact behaviors (anogenital exploration, crawling over/under) with a novel male peer target. The lack of interest in social contacts induced by PCP agrees with observations from other laboratories (Sams-Dodd, 1995, 1997, 1998; Qiao et al, 2001). Furthermore, the ability of OT to normalize the diminished social interaction in the chronic PCP model of schizophrenia is especially relevant as it confirms findings of symptom improvement noted when a bolus of OT was infused into the peripheral circulation of schizophrenic patients (Bujanow, 1974).

The effects of OT and AVP on male rodent social behaviors have been amply documented (Insel and Young, 2000; Ferguson et al, 2002). This report demonstrates the selective ability of OT to restore normal levels of social interaction in rodents with markedly diminished social behavior when infused into a brain site known to play a role in social behavior. These results expand upon an observation by Witt et al (1992), who noted that the increase in social interaction they attributed to repeated intracerebroventricular (icv) OT infusion was independent of sexual interest. After chronic icv OT infusion, male rats displayed significantly increased social interaction behaviors, specifically physical contact, with both cycling and ovariectomized female rats, but these male rats did not exhibit increased sexual behaviors with either target female rat nor did they exhibit altered open field behavior. Thus, OT in the CeA of the male brain may be the substrate and region, respectively, that mediate specific interest in asexual (male-male, male-ovariectomized female) social interactions. An acute dose may be sufficient to increase interaction by overcoming a presumed deficiency in PCP-treated rats, but chronic infusions of OT may be required to drive interaction levels higher in phenotypically normal male rats.

The inability of AVP to improve social function in chronic PCP-treated male rats merits further comment. A recent published study (Tanaka et al, 2003) reported that administration of a chronic low dose $(2 \mathrm{mg} / \mathrm{kg})$ of PCP to Wistar rats was associated with diminished social interaction and lowered $\mathrm{V} 1 \mathrm{aR}$ binding in several brain regions. In contrast to our data, their study did not, however, find a decrease in V1aR binding within the CeA. This discrepancy could be attributable to interstrain variability or to methodological differences between the studies. It is possible that Sprague-Dawley rats express PCP-induced changes in different brain regions from those altered in Wistar rats. A more striking difference between the studies is the elapsed time from the final injection of PCP to the onset of testing. Tanaka and co-workers tested social interaction behavior $45 \mathrm{~min}$ after the final dose of PCP; all rats in the current study were tested $72 \mathrm{~h}$ after their last PCP injection. Repeated administration of PCP precipitate behavioral and neurochemical changes that endure beyond the termination of drug treatment (Sturgeon et al, 1982; Jentsch et al, 1997, 1999; Qiao et al, 2001). These changes appear to be neuroplastic because the behavioral and neurochemical changes are present in the animals without further drug treatment. Administration of PCP within $1 \mathrm{~h}$ of testing is known to disrupt social interaction behavior (Sams-Dodd, 1995, 1997). Furthermore, since PCP is a NMDA receptor antagonist, and activation of NMDA receptors stimulates acute release of AVP from the hypothalamus (Swenson et al, 1998), the behavioral and binding data in the Tanaka et al study may reflect the acute effects of NMDA antagonism within the hypothalamus. Our findings that hypothalamic AVP mRNA levels were unchanged $72 \mathrm{~h}$ after the final PCP dose and the failure of any AVP infusion into the CeA to affect social interactions, strongly suggest that vasopressinergic function may not be associated with decreased social behaviors. Brattleboro rats, a naturally occurring rat strain with a total absence of functional AVP, exhibit social behaviors that are qualitatively and quantitatively similar to control AVP-intact Long-Evans male rats (Lee and Koenig, unpublished observations) further supporting this proposition.

We also report here that OT mRNA is reduced in the PVN of animals following chronic PCP administration and that there are marked changes in OT receptor binding. It is possible that the OT mRNA changes are not correlated with an overall decrease in OT peptide. Until rigorous quantitative studies are undertaken to evaluate the OT content of tissue from the PVN and CeA of chronic PCP-treated rats, the OT deficiency theory is supported by indirect evidence and remains hypothetical. Furthermore, the lack of a finding in AVP mRNA is offered with the caveat that AVP mRNA is so highly expressed in hypothalamic structures that subtle increases or decreases might be undetectable using in situ hybridization histochemistry. Assays of actual hypothalamic AVP and OT content are certainly warranted as a future direction of this research.

Researchers have theorized that OT is intimately involved the rewarding effects of touch (for a review, Uvnas-Moberg, 1998). Since OT-enhanced grooming in rats is suppressed following dopamine receptor blockade in (or ablation of) the nucleus accumbens (Drago et al, 1986), future microdialysis studies should examine the possible relationship of OT release in the male rat brain and engagement in physical nonsexual contacts (Drago et al, 1986).

In the present studies, diminished social interaction behavior is apparent $72 \mathrm{~h}$ after the final dose of a 14-day PCP treatment regimen and it is possible that this withdrawal from PCP caused a shift to a more anxious or depressed phenotype. However, other behavioral paradigms (the open field and light/dark emergence tests), which are designed to assess anxiety, failed to demonstrate a difference between PCP-treated rats and their appropriate control peers. Even within the social interaction testing itself, there were no incidences of freezing or fear-associated vocalizations in any subject. The PCP-treated rats were ambulatory in the arena but failed to engage in the sustained bouts of social behaviors apparent in unstressed control or chronic saline-treated control male rats, similar to the findings of Qiao et al (2001). While we have not determined the effects of antidepressant drugs in the present studies, studies by Noda et al (1997) and SamsDodd (1998) would suggest that antidepressant medications would not modify the chronic PCP-induced behaviors we are investigating. Further studies may be warranted in this area, however.

Like Witt et al (1992), we also observed no changes in open field measures of anxiety after central OT infusions; this finding serves as further evidence that the effect of OT infusions on behavior (as well as the ultimate cause of the social deficit) are not the outcome of a generalized change in the emotionality of these rats. An anxiolytic effect of OT 
has been reported in female rodents (McCarthy et al, 1996). Given the ability of estrogen to modulate the OT system (Bale et al, 1995), it may be that this action of OT is only manifested in the presence of higher levels of estrogen than are observed in male rats. It should be noted that the findings reported here are after an acute local infusion of OT into the CeA, and those of Witt et al (1992) represent the outcome of continuous icv OT infusion for 10 days. In comparing their results to those obtained in acute studies, the authors noted that a chronic paradigm may be necessary to elevate responses of phenotypically normal male rats, but that acute infusion paradigms may suffice in restoring behaviors associated with OT deficiencies or OTR blockade. Therefore, the success of OT in restoring social interaction in this animal model of schizophrenia may be indirect confirmation of a hypothesized OT deficiency created by the chronic PCP administration paradigm.

Previous research has shown that only atypical antipsychotic drugs abolish social interaction differences in chronic PCP-treated animals (Sams-Dodd, 1998; Qiao et al, 2001); benzodiazepines, which may increase social interaction, do not restore normal behavior after chronic PCP (Sams-Dodd, 1998). It has also been shown that the atypical antipsychotic agent, clozapine reverses social deficits in two other animal models of schizophrenia, namely the NMDA receptor knockout mice (Mohn et al, 1999) and in adult rats with excitotoxin lesions of the ventral hippocampus (SamsDodd et al, 1997). Haloperidol failed to reverse the social withdrawal in all three of these schizophrenia models. These findings are consistent with clinical observations that the atypical antipsychotic clozapine normalizes some of the negative symptoms of schizophrenia, while haloperidol fails to show significant effects on these same symptoms (Corrigan et al, 2003). Interestingly, clozapine but not haloperidol, enhances OT release from central nervous system neurons (Uvnas-Moberg et al, 1992). The data presented here would suggest that the potential therapeutic effects of clozapine on the negative symptoms of schizophrenia may, in fact, be mediated by alterations in the central oxytocinergic system and identify the CeA as a potential site for this action. These findings also point to the possible use of central oxytocinergic receptor agonists as treatments for some aspects of the behavioral deficits associated with schizophrenia, especially if the actions of the agents could be focused toward central nervous system targets. One possible mechanism to minimize undesirable peripheral actions of oxytocinergic agents would be to utilize an intranasal route of administration.

\section{REFERENCES}

Akbarian S, Sucher NJ, Bradley D, Tafazzoli A, Trinh D, Hetrick WP et al (1996). Selective alterations in gene expression for NMDA receptor subunits in prefrontal cortex of schizophrenics. J Neurosci 16: 19-30.

Azorin JM, Spiegel R, Remington G, Vanelle JM, Pere JJ, Giguere M et al (2001). A double-blind comparative study of clozapine and risperidone in the management of severe chronic schizophrenia. Am J Psychiatry 158: 1305-1313.

Bale TL, Pedersen CA, Dorsa DM (1995). CNS oxytocin receptor mRNA expression and regulation by gonadal steroids. Adv Exp Med Biol 395: 269-280.
Beckmann H, Lang RE, Gattaz WF (1985). Vasopressin-oxytocin in cerebrospinal fluid of schizophrenic patients and normal controls. Psychoneuroendocrinology 10: 187-191.

Bernstein HG, Jirikowski GF, Heinemann A, Baumann B, Hornstein C, Danos P et al (2000). Low and infrequent expression of nitric oxide synthase/NADPH-diaphorase in neurons of the human supraoptic nucleus: a histochemical study. J Chem Neuroanatomy 20: 177-183.

Bernstein HG, Stanarius A, Baumann B, Henning H, Krell D, Danos $\mathrm{P}$ et al (1998). Nitric oxide synthase-containing neurons in the human hypothalamus: reduced number of immunoreactive cells in the paraventricular nucleus of depressive patients and schizophrenics. Neuroscience 83: 867-875.

Bowers G, Cullinan WE, Herman JP (1998). Region-specific regulation of glutamic acid decarboxylase (GAD) mRNA expression in central stress circuits. J Neurosci 18: 5938-5947.

Braff DL, Geyer MA (1990). Sensorimotor gating and schizophrenia. Human and animal model studies. Arch Gen Psychiatry 47: $181-188$.

Brambilla F, Aguglia E, Massironi R, Maggioni M, Grillo W, Castiglioni $\mathrm{R}$ et al (1986). Neuropeptide therapies in chronic schizophrenia: TRH and vasopressin administration. Neuropsychobiology 15: 114-121.

Brambilla F, Bondiolotti GP, Maggioni M, Sciascia A, Grillo W, Sanna F et al (1989). Vasopressin (DDAVP) therapy in chronic schizophrenia: effects on negative symptoms and memory. Neuropsychobiology 20: 113-119.

Buchanan RW, Breier A, Kirkpatrick B, Ball P, Carpenter Jr WT (1998). Positive and negative symptom response to clozapine in schizophrenic patients with and without the deficit syndrome. Am J Psychiatry 155: 751-760.

Bujanow W (1974). Is oxytocin an anti-schizophrenic hormone? Can J Psychiatry 19: 323.

Corrigan PW, Reinke RR, Landsberger SA, Charate A, Toombs GA (2003). The effects of atypical antipsychotic medications on psychosocial outcomes. Schizophrenia Res 63: 97-101.

Drago F, Caldwell JD, Pedersen CA, Continella G, Scapagnini U, Prange Jr AJ (1986). Dopamine neurotransmission in the nucleus accumbens may be involved in oxytocin-enhanced grooming behavior of the rat. Pharmacol Biochem Behav 24: 1185-1188.

Elman I, Lukas S, Shoaf SE, Rott D, Adler C, Breier A (2003). Effects of acute metabolic stress on the peripheral vasopressinergic system in schizophrenia. J Psychopharmacol 17: 317-323.

Evins AE, Amico E, Posever TA, Toker R, Goff DC (2002). $\mathrm{D}$-Cycloserine added to risperidone in patients with primary negative symptoms of schizophrenia. Schizophrenia Res 56: 19-23.

Feifel D, Priebe K (2001). Vasopressin-deficient rats exhibit sensorimotor gating deficits that are reversed by subchronic haloperidol. Biol Psychiatry 50: 425-433.

Feifel D, Reza T (1999). Oxytocin modulates psychotomimeticinduced deficits in sensorimotor gating. Psychopharmacology (Berlin) 141: 93-98.

Ferguson JN, Young LJ, Insel TR (2002). The neuroendocrine basis of social recognition. Front Neuroendocrinol 23: 200-224.

File SE, Hyde JR (1979). A test of anxiety that distinguishes between the actions of benzodiazepines and those of other minor tranquilisers and of stimulants. Pharmacol Biochem Behav 11: 65-69.

Finlay JM (2001). Mesoprefrontal dopamine neurons and schizophrenia: role of developmental abnormalities. Schizophrenia Bull 27: 431-442.

Francis DD, Young LJ, Meaney MJ, Insel TR (2002). Naturally occurring differences in maternal care are associated with the expression of oxytocin and vasopressin (V1a) receptors: gender differences. J Neuroendocrinol 14: 349-353.

Frederiksen SO, Ekman R, Gottfries CG, Widerlov E, Jonsson S (1991). Reduced concentrations of galanin, arginine vasopressin, 
neuropeptide $\mathrm{Y}$ and peptide $\mathrm{YY}$ in the temporal cortex but not in the hypothalamus of brains from schizophrenics. Acta Psychiatr Scand 83: 273-277.

Gao XM, Sakai K, Roberts RC, Conley RR, Dean B, Tamminga CA (2000). Ionotropic glutamate receptors and expression of $\mathrm{N}$ methyl-D-aspartate receptor subunits in subregions of human hippocampus: effects of schizophrenia. Am J Psychiatry 157: 1141-1149.

Glovinsky D, Kalogeras KT, Kirch DG, Suddath R, Wyatt RJ (1994). Cerebrospinal fluid oxytocin concentration in schizophrenic patients does not differ from control subjects and is not changed by neuroleptic medication. Schizophrenia Res 11: 273-276.

Gurtman CG, Morley KC, Li KM, Hunt GE, McGregor IS (2002). Increased anxiety in rats after 3, 4-methylenedioxymethamphetamine: association with serotonin depletion. Eur J Pharmacol 446: 89-96.

Hanania T, Hillman GR, Johnson KM (1999). Augmentation of locomotor activity by chronic phencyclidine is associated with an increase in striatal NMDA receptor function and an upregulation of the NR1 receptor subunit. Synapse 31: 229-239.

Heresco-Levy U, Ermilov M, Lichtenberg P, Bar G, Javitt DC (2004). High-dose glycine added to olanzapine and risperidone for the treatment of schizophrenia. Biol Psychiatry 55: 165-171.

Humphries C, Mortimer A, Hirsch S, de Belleroche J (1996). NMDA receptor mRNA correlation with antemortem cognitive impairment in schizophrenia. Neuroreport 7: 2051-2055.

Iager AC, Kirch DG, Bigelow LB, Karson CN (1986). Treatment of schizophrenia with a vasopressin analogue. Am J Psychiatry 143: 375-377.

Insel TR, Young LJ (2000). Neuropeptides and the evolution of social behavior. Curr Opin Neurobiol 10: 784-789.

Javitt DC, Zukin SR (1991). Recent advances in the phencyclidine model of schizophrenia. Am J Psychiatry 148: 1301-1308.

Jentsch JD, Taylor JR, Elsworth JD, Redmond Jr DE, Roth RH (1999). Altered frontal cortical dopaminergic transmission in monkeys after subchronic phencyclidine exposure: involvement in frontostriatal cognitive deficits. Neuroscience 90: 823-832.

Jentsch JD, Tran A, Le D, Youngren KD, Roth RH (1997). Subchronic phencyclidine administration reduces mesoprefrontal dopamine utilization and impairs prefrontal cortical-dependent cognition in the rat. Neuropsychopharmacology 17: 92-99.

Koenig JI, Elmer GI, Shepard PD, Lee PR, Mayo C, Joy B et al (2005). Prenatal exposure to a repeated variable stress paradigm elicits behavioral and neuroendocrinological changes in the adult offspring: potential relevance to schizophrenia. Behav Brain Res 156: 251-261.

Krystal JH, Karper LP, Seibyl JP, Freeman GK, Delaney R, Bremner JD et al (1994). Subanesthetic effects of the noncompetitive NMDA antagonist, ketamine, in humans. Psychotomimetic, perceptual, cognitive, and neuroendocrine responses. Arch Gen Psychiatry 51: 199-214.

Lahti AC, Koffel B, LaPorte D, Tamminga CA (1995). Subanesthetic doses of ketamine stimulate psychosis in schizophrenia. Neuropsychopharmacology 13: 9-19.

Lee PR, Brady D, Koenig JI (2003). Corticosterone alters $N$-methylD-aspartate receptor subunit mRNA expression before puberty. Mol Brain Res 115: 55-62.

Legros JJ, Gazzotti C, Carvelli T, Franchimont P, Timsit-Berthier $\mathrm{M}$, von Frenckell $\mathrm{R}$ et al (1992). Apomorphine stimulation of vasopressin- and oxytocin-neurophysins. Evidence for increased oxytocinergic and decreased vasopressinergic function in schizophrenics. Psychoneuroendocrinology 17: 611-617.

Lijam N, Paylor R, McDonald MP, Crawley JN, Deng CX, Herrup K et al (1997). Social interaction and sensorimotor gating abnormalities in mice lacking Dvl1. Cell 90: 895-905.

Linkowski P, Geenen V, Kerkhofs M, Mendlewicz J, Legros JJ (1984). Cerebrospinal fluid neurophysins in affective illness and in schizophrenia. Eur Arch Psychiatry Neurol Sci 234: 162-165.
Lipska BK, Weinberger DR (2000). To model a psychiatric disorder in animals: schizophrenia as a reality test. Neuropsychopharmacology 23: 223-239.

Long JM, LaPorte P, Paylor R, Wynshaw-Boris A (2004). Expanded characterization of the social interaction abnormalities in mice lacking Dvl1. Genes Brain Behav 3: 51-62.

Mai JK, Berger K, Sofroniew MV (1993). Morphometric evaluation of neurophysin-immunoreactivity in the human brain: pronounced inter-individual variability and evidence for altered staining patterns in schizophrenia. J Hirnforsch 34: 133-154.

Malhotra AK, Pinals DA, Adler CM, Elman I, Clifton A, Pickar D et al (1997). Ketamine-induced exacerbation of psychotic symptoms and cognitive impairment in neuroleptic-free schizophrenics. Neuropsychopharmacology 17: 141-150.

Mansbach RS, Geyer MA (1989). Effects of phencyclidine and phencyclidine biologs on sensorimotor gating in the rat. Neuropsychopharmacology 2: 299-308.

McCarthy MM, McDonald CH, Brooks PJ, Goldman D (1996). An anxiolytic action of oxytocin is enhanced by estrogen in the mouse. Physiol Behav 60: 1209-1215.

Miyakawa T, Leiter LM, Gerber DJ, Gainetdinov RR, Sotnikova TD, Zeng $\mathrm{H}$ et al (2003). Conditional calcineurin knockout mice exhibit multiple abnormal behaviors related to schizophrenia. Proc Natl Acad Sci USA 100: 8987-8992.

Mohn AR, Gainetdinov RR, Caron MG, Koller BH (1999). Mice with reduced NMDA receptor expression display behaviors related to schizophrenia. Cell 98: 427-436.

Newcomer JW, Farber NB, Jevtovic-Todorovic V, Selke G, Melson AK, Hershey T et al (1999). Ketamine-induced NMDA receptor hypofunction as a model of memory impairment and psychosis. Neuropsychopharmacology 20: 106-118.

Noda Y, Mamiya T, Furukawa H, Nabeshima T (1997). Effects of antidepressants on phencyclidine-induced enhancement of immobility in a forced swimming test in mice. Eur J Pharmacol 324: $135-140$.

Noda Y, Yamada K, Furukawa H, Nabeshima T (1995). Enhancement of immobility in a forced swimming test by subacute or repeated treatment with phencyclidine: a new model of schizophrenia. Br J Pharmacol 116: 2531-2537.

Paxinos G, Watson C (1986). The Rat Brain in Stereotaxic Coordinates 2nd edn. Academic Press: Orlando, FL.

Qiao H, Noda Y, Kamei H, Nagai T, Furukawa H, Miura H et al (2001). Clozapine, but not haloperidol, reverses social behavior deficit in mice during withdrawal from chronic phencyclidine treatment. Neuroreport 12: 11-15.

Raskind MA, Courtney N, Murburg MM, Backus FI, Bokan JA, Ries RK et al (1987). Antipsychotic drugs and plasma vasopressin in normals and acute schizophrenic patients. Biol Psychiatry 22: 453-462.

Sams-Dodd F (1995). Distinct effects of d-amphetamine and phencyclidine on the social behaviour of rats. Behav Pharmacol 6: 55-65.

Sams-Dodd F (1997). Effect of novel antipsychotic drugs on phencyclidine-induced stereotyped behaviour and social isolation in the rat social interaction test. Behav Pharmacol 8: 196-215.

Sams-Dodd F (1998). Effects of diazepam, citalopram, methadone and naloxone on PCP-induced stereotyped behaviour and social isolation in the rat social interaction test. Neurosci Biobehav Rev 23: 287-293.

Sams-Dodd F, Lipska BK, Weinberger DR (1997). Neonatal lesions of the rat ventral hippocampus result in hyperlocomotion and deficits in social behavior in adulthood. Psychopharmacology (Berlin) 132: 303-310.

Sherman TG, Day R, Civelli O, Douglass J, Herbert E, Akil H et al (1988). Regulation of hypothalamic magnocellular neuropeptides and their mRNAs in the Brattleboro rat: coordinate responses to further osmotic challenge. J Neurosci 8: 3785-3796. 
Sturgeon RD, Fessler RG, London SF, Meltzer HY (1982). Behavioral effects of chronic phencyclidine administration in rats. Psychopharmacology (Berlin) 76: 52-56.

Swenson KL, Badre SE, Morsette DJ, Sladek CD (1998). N-methylD-aspartic acid stimulation of vasopressin release: role in osmotic regulation and modulation by gonadal steroids. $J$ Neuroendocrinol 10: 679-685.

Swerdlow NR, Braff DL, Taaid N, Geyer MA (1994). Assessing the validity of an animal model of deficient sensorimotor gating in schizophrenic patients. Arch Gen Psychiatry 51: 139-154.

Swerdlow NR, Caine SB, Geyer MA (1992). Regionally selective effects of intracerebral dopamine infusion on sensorimotor gating of the startle reflex in rats. Psychopharmacology 108: 189-195.

Szot P, Bale TL, Dorsa DM (1994). Distribution of messenger RNA for the vasopressin V1a receptor in the CNS of male and female rats. Mol Brain Res 24: 1-10.

Tanaka K, Suzuki M, Sumiyoshi T, Murata M, Tsunoda M, Kurachi M (2003). Subchronic phencyclidine administration alters central vasopressin receptor binding and social interaction in the rat. Brain Res 992: 239-245.

Tsai G, Yang P, Chung LC, Lange N, Coyle JT (1998). D-serine added to antipsychotics for the treatment of schizophrenia. Biol Psychiatry 44: 1081-1089.

Uvnas-Moberg K (1998). Oxytocin may mediate the benefits of positive social interaction and emotions. Psychoneuroendocrinology 23: 819-835.

Uvnas-Moberg K, Alster P, Svensson TH (1992). Amperozide and clozapine but not haloperidol or raclopride increase the secretion of oxytocin in rats. Psychopharmacology 109: 473-476.

Varty GB, Geyer MA (1998). Effects of isolation rearing on startle reactivity, habituation, and prepulse inhibition in male Lewis, Sprague-Dawley, and Fischer F344 rats. Behav Neurosci 112: 1450-1457.

Wang C, Showalter VM, Hillman GR, Johnson KM (1999). Chronic phencyclidine increases NMDA receptor NR1 subunit mRNA in rat forebrain. J Neurosci Res 55: 762-769.

Witt DM, Winslow JT, Insel TR (1992). Enhanced social interactions in rats following chronic, centrally infused oxytocin. Pharmacol Biochem Behav 43: 855-861. 